\title{
NOTAS EPISTEMOLÓGICAS: NIKLAS LUHMANN E A TRADIÇÃO SOCIOLÓGICA
}

EPISTEMOLOGICAL NOTES:

NIKLAS LUHMANN AND THE SOCIOLOGICAL TRADITION

Léo Peixoto Rodrigues ${ }^{1}$

\begin{abstract}
Resumo: A partir de um breve relato sobre as abordagens teóricas clássicas, tais como as de Émile Durkheim: positivista-funcionalista; de Max Weber: interpretativista; de Karl Marx: o materialismo histórico dialético; além da proposta estruturalista francesa, o presente artigo tem por objetivo pontuar, de modo mais ou menos comparativo, a proposta teórico-epistemológica de Niklas Luhmann, considerando categorias conceituais como: sujeito/objeto, ciência/ ideologia, normatividade, ontologia, teleologia. Nesse sentido, busca-se destacar aspectos da proposta teórico-epistemológica Luhmanniana e algumas das suas implicações com relação às abordagens teóricas que fazem parte da tradição do conhecimento sociológico.

Palavras-Chave: Sociologia clássica; Sociologia sistêmica; Niklas Luhmann; Epistemologia; Sociologia do conhecimento
\end{abstract}

\footnotetext{
[1] Doutor em Sociologia, professor adjunto do Instituto de Sociologia e Política e Coordenador do Programa de Pós-Graduação em Ciências Sociais da Universidade Federal de Pelotas - UFPel, Pelotas, Brasil, e-mail: leo.peixoto@gmail.com
} 
Abstract: This article, from a brief overview of the classical theoretical approaches such as Emile Durkheim: positivist/functionalist; Max Weber: epistemological approach; Karl Marx: the historical and dialectical materialism, and also the French structuralist, wants to compare the theoretical-epistemological Niklas Luhmann approach, taking into account conceptual categories such as subject/ object, science/ ideology, ontology, teleology. In this sense, we seek to highlight aspects of the theoretical-epistemological luhmannian discussion and some of the implications for the classical theoretical approaches.

Keywords: Classical sociology; Sociology of the system; Niklas Luhmann; Epistemology; Sociology of knowledge

\section{INTRODUÇÃO}

Este artigo está dividido em duas partes principais: a primeira faz um pequeno relato sobre três abordagens teóricas clássicas, destacando principalmente aspectos de fundamento e de método. Evidentemente tais abordagens, que buscam ir diretamente para uma discussão que envolve a relação sujeito/objeto e "lugar epistêmico" de onde referenciam suas construções teóricas, não têm por objetivo fazer uma exposição sistemática dessas teorias clássicas, mas sim apontar e destacar alguns dos aspectos que Luhmann, com sua proposta sistêmica, critica e busca superar. A segunda parte pontuará, de modo mais ou menos comparativo, a proposta teórica de Niklas Luhmann, considerando categorias conceituais, tais como: sujeito/ objeto, ciência/ideologia, normatividade, ontologia, teleologia.

Este artigo, portanto, tem como objetivo destacar aspectos da proposta teórico-epistemológica Luhmanniana e algumas das implicações com relação às abordagens teóricas que remontam a tradição do conhecimento sociológico. As abordagens tradicionais a serem pontuadas são: a) a proposta positivista-funcionalista, que teve em 
Émile Durkheim um de seus mais ilustres representantes, embora, mesmo antes dele, já houvesse se constituído em marco a filosofia positiva de Auguste Comte, o organicismo evolucionista de Herbert Spencer, dentre outras; b) a proposta de Max Weber, que, frente à radicalidade da abordagem Luhmanniana, mesmo sendo interpretativista e histórica, permanece muito vinculada a uma sociologia da ação, mais especificamente a uma perspectiva individualista metodológica; c) a proposta dialética materialista, principalmente no que concerne aos aspectos humanista e econômico, bem como a algumas categorias conceituais centrais da teoria marxiana, tais como: alienação, emancipação e verdade e método; d) a proposta estruturalista francesa, uma vez que esse movimento teórico, despontado na França, foi buscar fundamentos epistemológicos na linguística de Ferdinand de Saussure, como uma proposta literalmente revolucionária para a teoria social da época.

\section{DURKHEIM E O POSITIVISMO FUNCIONALISTA}

Durkheim, ao propor a Sociologia como disciplina científica, foi obrigado a dar conta de pelo menos três importantes problemas epistemológicos. O primeiro estava posto pela Psicologia, que, no final dos oitocentos, já apresentava certo grau de desenvolvimento no âmbito das disciplinas do conhecimento científico. Para ela, o sujeito poderia ser considerado como o átomo da construção do social; sujeitos "ideais" produziriam uma sociedade "ideal". O segundo problema consistia no fato de que o objeto da sociologia, no sentido estrito, não poderia ser a sociedade, dada a sua heterogeneidade e a dificuldade de se estabelecer limites. Assumi-la como objeto colocaria em relevo a questão de suas inúmeras diferenciações que não são ou não estão claramente demarcadas. A sociedade como um todo, pois, quando pesquisada, nada ou muito pouco revelaria, devido à incapacidade de se captar e explicar tais diferenciações. O terceiro problema epistemológico constituía-se no fato de que a Ciência à época, sobretudo de tradição francesa, exigia a não sobreposição 
do sujeito pesquisador e do objeto pesquisado. Em outros termos, a crítica oriunda do ambiente intelectual acadêmico francês, muito influenciada pelo positivismo comteano, apontava para a necessidade de um corte, uma separação radical entre sujeito conhecedor e objeto conhecido.

A saída encontrada para esses problemas foi a de Durkheim propor o fato social como representação coletiva, como objeto de estudo da sociologia. O prefácio da segunda edição da sua obra "As Regras do Método Sociológico" (1982) constitui-se, até os dias de hoje, em uma importante defesa à construção dos fatos sociais como aquilo que deve ser conhecido para que se produza uma genuína ciência do social.

Sendo assim, as diferentes representações coletivas - uma forma de também perceber as instituições - conseguiam, ao mesmo tempo, contemplar as diferenciações da sociedade por um lado e a separação do sujeito pesquisador do objeto pesquisado por outro lado, uma vez que o pesquisador não estaria envolvido diretamente com as diferentes representações sociais. Assim, a sociologia nasce na academia dentro de um esquema epistemológico caudatário da chamada received view, cujo método observacional e a distinção entre sujeito e objeto são indispensáveis. Foi a filosofia positiva de Comte, claramente descrita em seu "Curso de filosofia positiva" (1983), que fez essa transposição do realismo epistemológico das ciências naturais (astronomia, física, química e biologia) para as ciências sociais, em específico, para a sociologia.

Portanto, a fundamentação epistemológica da sociologia Durkheimiana, isto é, o pilar de sustentação da produção de um conhecimento verdadeiro, estava na possibilidade de objetivação (coisificação) da realidade observada e na separação radical entre sujeito e objeto. Os fatos sociais, ou as representações coletivas, como propunha Durkheim, constituíam-se em realidades coletivas objetivadas e observáveis pelo sociólogo. Aí repousava toda a garantia de um conhecimento social cientificamente verdadeiro para as sociedades modernas que estavam velozmente despontando. 
Deste modo, é possível que se pontue alguns tópicos de caráter epistemológico e metodológico do pensamento metódico durkheimiano, os quais a teoria luhmanniana irá passar ao largo, constituindo-se em um sistema de ideias completamente distinto. Em Durkheim temos que:

a) A construção de seu objeto, constituído pelos fatos sociais, exige a separação radical entre o sujeito conhecedor e objeto conhecido.

b) Essa perspectiva epistemológica é caudatária de toda uma tradição epistemológica analítica, também conhecida como realismo epistemológico.

c) Corolariamente, os fatos sociais tornam-se "coisas" que podem ser conhecidas na sua integralidade através de um observador externo privilegiado.

d) A fundamentação epistemológica que assegura o conhecimento "verdadeiro" repousa nos métodos indutivo (observacional) e dedutivo (racionalismo e construção de hipóteses).

e) As instituições, como representação coletiva, devem ser conhecidas em consonância com função (finalidade) que exercem na sociedade, para a qual foram criadas.

Embora as ciências sociais de modo geral e a sociologia de modo específico, nos dias de hoje, apresentem uma variada gama de métodos para o conhecimento de diversos fenômenos sociais, o método positivo, isto é, aquele que se calca na indução/dedução, ainda tem sido amplamente utilizado, seja na sua forma mais "dura", seja na sua forma mais "branda". Despir-se das pré-noções, como propunha Durkheim, e separar o sujeito do objeto, mesmo conhecendo-se as dificuldades e certamente a ingenuidade que, por vezes, encerra esse esforço, sem dúvida, ainda continua sendo muito utilizado na pesquisa acadêmica atual. 


\section{WEBER E A COMPREENSÃO DA AÇÃO SOCIAL}

Antes de se adentrar a perspectiva teórica weberiana, é necessário que se faça um breve comentário, destacando aspectos da tradição a qual Weber é tributário. No mesmo período em que se discutia na França de Auguste Comte a necessidade de as ciências sociais subordinarem-se ao mesmo método das ciências naturais - tal método havia se mostrado eficiente para as ciências da natureza - com o objetivo de encontrar as regularidades e leis constitutivas do social, Wilhelm Dilthey propunha, na Alemanha, em sua obra "Introdução às ciências do espírito", de 1883, que a "relação de exterioridade" que as ciências da natureza guardavam com o seu objeto fosse igualmente adotada no que se refere à "relação de interioridade" que as ciências sociais também apresentavam para com seu objeto. Para Dilthey, o mundo da natureza era essencialmente estranho ao homem, ao passo que o mundo humano constituía-se numa experiência vivida e, por este motivo, passível de compreensão. Assim, a ciência da natureza deveria ser explicada (Erklären), ao passo que a ciência do espírito deveria ser compreendida (Verstehen). Essa perspectiva hermenêutica teve influência direta de Schleiermacher, a quem Dilthey considerava como o "Kant da Hermenêutica" (Levine, 1997).

Weber, ao construir sua própria perspectiva, concorda com Dilthey sobre a legitimidade da diferenciação das ciências da natureza e das ciências sociais. Entretanto, ele mesmo discordava da perspectiva de que a ciência do espírito deveria ser compreendida somente pela intuição imediata e propunha também a compreensão por meio de uma construção metodológica. Essa perspectiva weberiana também se contrapunha à percepção neokantista de Wilhelm Windelband, para quem os valores sociais deveriam ser considerados absolutos, para que pudessem se tornar objeto do estudo científico. Weber, ao ressaltar a pluralidade de valores existentes em uma determinada cultura, acusa a posição de Windelband como metafísica e, portanto, distante da possibilidade de se produzir conhecimento científico (Andrade; Pive; Pizzi, 2007). 
Max Weber tem sido considerado o interprete de toda uma tradição do pensamento alemão que parte de Kant a Dilthey, este o influencia de modo significativo. Sofreu também influências indiretas, mais ou menos importantes, de pensadores tais como: Herder, Schleiermacher e Renke. Entretanto, Weber vivia o espírito iluminista da ciência, isto é, o espírito da necessidade de rigor metodológico e de distinção da filosofia no modus operandi, para a produção de conhecimento. Tanto é que propõe a famosa distinção entre idéia de valor e juízo de valor. Se a preocupação com o rigor científico, por um lado, e a sua proposta hermenêutica, por outro lado, foram suas maiores qualidades como pensador e cientista social, também podem ser consideradas, até os dias de hoje, como uma das dimensões mais frágeis de seu arcabouço teórico segundo seus principais intérpretes, no que se refere a questões epistemológicas.

Max Weber (2004), ao propor a "ação social" como objeto de conhecimento da sociologia, afirmando que: "A ação social orientase pelo comportamento de outros [e que] outros podem ser indivíduos conhecidos ou uma multiplicidade indeterminada de pessoas completamente desconhecidas" (2004, p. 13-14) e, ao mesmo tempo, utilizar como método para o conhecimento dessa ação social, a compreensão, isto é, Verstehen, lança mão, assim, da hermenêutica como fundamentação da sua proposta teórica. Para Weber, era necessário que o sociólogo, ao produzir conhecimento científico social, compreendesse a racionalidade intrínseca de toda ação. Ao combinar seu objeto a seu método, afirma:

"Sociologia (no sentido aqui entendido desta palavra empregada com tantos significados diversos) significa: uma ciência que pretende compreender interpretativamente a ação social e assim explicá-Ia causalmente em seu curso e em seus efeitos. Por "ação” entende-se, neste caso, um comportamento humano (tanto faz tratar-se de um fazer externo ou interno, de omitir ou permitir) sempre que e na medida em que o agente ou os agentes o relacionem com um sentido sub- 
jetivo. Ação "social", por sua vez, significa uma ação que, quanto a seu sentido visado pelo agente ou os agentes, se refere ao comportamento de outros, orientando-se por este em seu curso." (Weber, 2004, p. 3-4).

A dimensão de interpretação e de subjetividade, a qual permite esse espaço hermenêutico fundacional, encontra-se tanto no sujeito conhecedor como no objeto a ser conhecido. Ao se examinar um pouco mais detalhadamente o excerto anterior, é possível verificar que, quando Weber afirma que a sociologia deve "compreender interpretativamente a ação social", tem-se, então, por um lado, o sujeito pesquisador com "espaço" para interpretação, isso significa que elementos da subjetividade do próprio pesquisador podem - em certa medida devem- fazer parte do conhecimento produzido; por outro lado, tem-se também a subjetividade do sentido visado pelo(s) agente(s). Evidentemente que essa proposição weberiana, que segue, de certo modo, a tradição alemã, distancia-se de uma postura positivista no que concerne à produção de conhecimento social, sobretudo ao compararmos com a proposta durkheimiana, e mesmo a spenceriana, cujos fundamentos estão fincados claramente numa abordagem epistemológica analítica.

No entanto, Weber não deixa suficientemente claro, segundo seus críticos, se o que deve ser compreendido são estados subjetivos de atores individuais, de atores coletivos, ou de ambos. Alguns autores, como Ritzer (1993), defendem que a compreensão refere-se a ambos, e que "a interpretação em escala cultural seria coerente com as teorias de longo alcance (como o funcionalismo estrutural), enquanto que, a perspectiva individual, seria apropriada para teorias no sentido estrito (como o interacionismo simbólico)" (Ritzer, 1993, p. 253). Fato é que, ao introduzir a noção de compreensão, Weber flexiona a rígida perspectiva positivista de uma verdade única que se estabelece para além do tempo e do espaço, a exemplo das leis gerais propostas para as ciências naturais. Entretanto, sua proposta teórico-metodológica para a produção de conhecimento científico 
social, mesmo contemplando uma dimensão hermenêutica interpretativa, tropeça em algumas dificuldades de cunho epistemológico que, de certo modo, dissipam-se na abordagem sistêmica proposta por Luhmann, quais sejam:

a) A questão da dificuldade ou da impossibilidade de o sujeito conhecedor garantir-se de que sua idéia de valor distinguese plenamente do seu juízo de valor para que possa buscar certo nível de objetividade do conhecimento científico.

b) O sentido visado pelo agente ou pelos agentes, que se refere ao comportamento de outros, como mencionou anteriormente Weber, quando captado pelo pesquisador, pressupõe, necessariamente, um sujeito conhecedor e um objeto conhecido, que, embora tematizem-se em determinados momento e espaço epistêmicos do processo de conhecimento, diferente da abordagem luhmanniana, ainda permitem que permaneça a dicotomia conhecedor/conhecido.

c) Corolariamente, a existência de um conhecedor e de algo a ser conhecido, mesmo que em determinados momentos ambos se interfecundem (reflexividade) para a construção de sentido(s), faz com que perdure, ainda assim, a possibilidade de crítica feita à epistemologia de orientação analítica durante boa parte do século XX.

d) Pode-se questionar quanto à existência da possibilidade de compreensão de uma determinada cultura, uma sociedade, ou mesmo um "sistema social", partindo-se exclusivamente da ação, isto é, quão é possível determinar os tipos, as diferenças, os limites de uma sociedade, tendo por base corolários de ações (individuais ou coletivas), cujos aspectos contingentes da própria historicidade podem implicar radicais descontinuidades naquilo que chamamos de social.

São incontáveis os estudos teóricos realizados sobre os clássicos da sociologia de todas as tradições, escolas ou correntes possíveis. Max Weber não foge à regra. Muito das críticas realizadas a 
esse autor recai sobre questões de natureza epistemológica e metodológica, as quais vão desde uma visão positivista da sua obra até uma perspectiva relativista e, portanto, não científica. Objetiva-se, entretanto, ressaltar aqui, em breves palavras, algumas considerações sobre possíveis aproximações epistemológicas existentes entre a hermenêutica, no sentido amplo - incluído também tudo aquilo que Weber traz dela para a sua distinção entre ciências da natureza e ciências sociais -, e a noção de autopoiésis.

$\mathrm{Na}$ hermenêutica moderna, o ato de conhecer remete necessariamente à noção de que o homem está permanentemente e reflexivamente significando e sendo significado pelo (e no) processo histórico, que se constitui na busca permanente de sentido. O próprio ato de compreender conduz o homem - sujeito do conhecimento - a aventurar-se naquilo que, para ele, ainda não lhe tem sentido. Como o sentido é um ato cognitivo que não pode partir exclusivamente de "fora", pois, como conhecimento, difere-se do realismo epistemológico, é necessário que o sujeito se construa (cognitivamente) enquanto constrói o social. Assim, epistemologicamente, é possível o estabelecimento de aproximações entre hermenêutica e autopoiésis, tomando-se por base a perspectiva construtivista dessas duas noções (Flickinger, 1994).

\section{MARX: ALIENAÇÃO E EMANCIPAÇÃO}

Não obstante as aproximações que a teoria dos sistemas de Niklas Luhmann possa ter com abordagens dialéticas - e mesmo com o sistema filosófico hegeliano ${ }^{1}$-, quando pensada à luz do materialismo histórico de Marx, os elementos de divergência teóricoepistemológicos são significativos e praticamente incomensuráveis. Pretende-se, aqui, como realizamos com os enfoques anteriores, apenas apontar, de forma breve, para algumas distinções flagrantes entre as duas teorias, ressaltando sempre questões de fundamento.

[1] Para Moeler (2006), por exemplo, existem diferenças significativas com relação à perspectiva teórica hegeliana, sobretudo no que diz respeito à "Fenomenologia do Espírito". Para esse autor, uma das semelhanças que se marca bem é o estilo e a ambição quanto ao projeto teórico. 
A leitura, a aprendizagem e o ensino da teoria marxiana, quando não vulgarizadas, apresentam um grau importante de dificuldade para a sua compreensão. Isso porque tal teoria envolve reflexões filosóficas, como por exemplo, a dialética hegeliana, o existencialismo humanista; e uma bem construída teoria econômica, como a teoria do valor, cujas raízes provêm da sua própria reflexão humanista e materialista histórica. Como não bastasse, Marx, a partir do estabelecimento de suas bases filosóficas e econômicas, vai em direção a reflexões de caráter eminentemente social quando aborda questões sobre o modo de produção, relações produtivas, culminando com importantes aportes no campo da teoria política. Pode-se dizer que o materialismo histórico dialético, quando concebido na interação das diferentes disciplinas que adentra e na articulação de categorias conceituais interdisciplinares, além da sua dimensão teórico-estética, apresenta-se coerente e intelectualmente muito sedutor.

Um dos pontos, talvez o de maior fragilidade e o mais criticado na teoria de Marx, tem sido a questão da sobredeterminação de todas as dimensões do social pela economia. A dialética materialista, como não poderia ser diferente, deu especial importância ao modo de produção capitalista e às relações de produção, como fundamentação de todo o edifício teórico marxiano. Nesse sentido, Marx desenvolveu determinados corolários teóricos que, de fato, têm ficado descobertos quando questionados a partir de um ponto de vista da fundamentação científica, independente do método que se aborde. Em seu primeiro manuscrito, por exemplo, "O trabalho alienado", o termo alienar, alienação e seus derivativos aparece mais de oitenta vezes em um manuscrito que possui em torno de vinte páginas. Isso não teria qualquer problema adicional, não fosse o fato de que a noção de alienação não consegue se fundamentar substantivamente. Ela aparece de modo tautológico, quase que na busca solipsista de garantir a si mesma. Na passagem abaixo, que constitui um dos parágrafos desse manuscrito, o termo e derivados aparecem dez vezes:

[1] Disponível em: http:/www.marxists.org/portugues/marx/1844/manuscritos/index.htm\#topp. 
"Até aqui consideramos a alienação do trabalhador somente sob um aspecto, qual seja o de sua relação com os produtos de seu trabalho. Não obstante, a alienação aparece não só como resultado, mas também como processo de produção, dentro da própria atividade produtiva. Como poderia o trabalhador ficar numa relação alienada com o produto de sua atividade se não se alienasse a si mesmo no próprio ato da produção? O produto é, de fato, apenas a síntese da atividade, da produção. Conseqüentemente, se o produto do trabalho é alienação, a própria produção deve ser alienação ativa - a alienação da atividade e a atividade da alienação. A alienação do objeto do trabalho simplesmente resume a alienação da própria atividade do trabalho." (Marx, 1844, p. XXIII).

Quando os estruturalistas propuseram que as diferentes sociedades e suas manifestações culturais, sociais, políticas etc., na verdade, obedeciam a uma lógica estruturante - momento esse em que Michel Foucault (1968) decreta a "morte do sujeito" -, fizeramno fundamentando essa posição na moderna teoria da linguagem. Posteriormente, os estruturalistas se deram conta que as estruturas não poderiam ser inexoravelmente estruturantes, posto que, se assim fosse, as sociedades não apresentariam qualquer mudança no decorrer do tempo, não evoluiriam. Daí surge o que hoje se chama de pósestruturalismo. Estar alienado, como no caso do excerto de Marx acima apresentado, é estar inescapavelmente estruturado; é a anulação irrevogável seja do indivíduo, seja do sujeito, seja da ação. O econômico de Marx, na perspectiva sistêmica, torna-se um sistema onipotente, absoluto, sem entorno e sem possibilidade de qualquer alteração. Luhmann (1998, p. 239), ao discutir a "individualidade dos sistemas psíquicos", afirma que "os pensadores neo-humanistas, até Hegel e Marx, naturalmente não se contentavam com a afirmação de que cada um é um indivíduo" e questiona: "como pode, então, encher de conteúdo esta generalidade meramente quantitativa, essa mera totalidade?". 
Dificuldade semelhante, no que se refere a questões epistemológicas e de fundamentação, é o conceito de "emancipação" presente no manuscrito "Propriedade privada e comunismo" '. Examine-se o seguinte excerto: "A anulação da propriedade privada é, pois, a emancipação completa de todos os atributos e sentidos humanos. Ela é essa emancipação porque esses atributos e sentidos tornaram-se humanos, tanto sob o ponto de vista subjetivo quanto sob o objetivo" (Marx, 1844, p. XXXIX). A primeira dificuldade está relacionada à crítica anterior feita por Luhmann, isto é, quem é que se emancipa, o indivíduo ou a coletividade? Se for o indivíduo considerando, inclusive, a época em que Marx escrevera, uma vez que Descartes, no século XVII, já havia "criado" o sujeito e dado voz a sua subjetividade -, a emancipação necessariamente dar-se-á de formas distintas, considerando justamente a subjetividade; se for a coletividade, corre-se o risco de não se chegar à emancipação, mas sim cair em outra alienação, ou seja, o surgimento de novos grilhões. Além desse fato, na proposta emancipatória de Marx, existe uma dimensão essencialista do humano, se não um essencialismo, uma ontologia do "sujeito social". De qualquer modo, o espaço de subjetividade e de contingência que permeia toda a dimensão cultural fica subsumido.

Marx, como todo pensador de seu tempo, estava vivendo um dos momentos mais apoteóticos do Iluminismo. Todos tinham a pretensão de falar verdadeiramente sobre o mundo, fosse ele natural ou social. Em o "Método da economia política" (1978), em mais uma das suas críticas aos economistas clássicos, Marx busca demonstrar o equívoco metodológico destes, propondo o seu método para os estudos econômicos: Diz ele:

“A população é uma abstração, se desprezarmos, por exemplo, as classes que a compões. Por seu lado, estas classes são uma palavra vazia de sentido se ignorarmos os elemen-

[1] Disponível em: http://www.marxists.org/portugues/marx/1844/manuscritos/index.htm\#topp [grifos do autor]. 
tos em que repousam, por exemplo: o trabalho assalariado, o capital, etc. (...) Assim se começássemos pela população, teríamos uma representação caótica do todo (...) O primeiro [método] constitui o caminho que foi historicamente seguido pela nascente economia (...) o último método é manifestamente o método cientifico exato." (Marx 1978, p.116 [grifos nossos]).

Na citação anterior, em que Marx demonstra a influência do pensamento dialético hegeliano nos economistas clássicos, uma vez que eles partiam de uma pura abstração para a formulação de conhecimento, é possível perceber a dimensão positivista - mesmo referindo-se ao método dialético - em torno da noção de verdadeiro, de exato. $\mathrm{O}$ mesmo acontece sempre que emprega o termo ideologia para designar o equívoco de posições individuais ou grupais, obliterando completamente qualquer espaço de subjetividade e de contingência. Não deveria a contingência estar presente na dialética seja materialista, seja idealista?

Não haveria maiores problemas na pretensão de cientificidade, de exatidão e de verdade, como por exemplo, em Durkheim, caso Marx tivesse mantido um fio condutor epistemológico e metodológico, sobretudo em questões capitais da sua obra. Entretanto, isso não aconteceu: o materialismo histórico dialético flerta, em diversos momentos do seu desenvolvimento, com o historicismo, com o realismo, com a hermenêutica, embora se autoproclame estritamente dialético. Nesse sentido, é possível destacar, de forma mais resumida, algum pontos centrais de incongruência com a proposta Luhmanniana, quais sejam:

a) A relação sistema/entorno pode pressupor elementos da dialética como um processo evolutivo; entretanto, nem o sistema nem o entorno encontram-se em lugar privilegiados na teoria, havendo uma esfera de indeterminação no processo de coevolução luhmanniana;

b) Luhmann tem explicitado constantemente o caráter não 
humanista da sua teoria. Na teoria dos sistemas, não existe opressor ou oprimido, o que existe são sistemas e entorno(s). Nesse sentido, não há possibilidade de sobredeterminar dada a autopoiésis;

c) As noções de alienação, de ideologia e de ontologia são vazias de sentido na teoria dos sistemas, uma vez que o conhecimento sempre é um autoconhecimento e pode emergir a partir de condições muito contingenciais, assim como podem ter uma durabilidade muito precária;

d) O mesmo se pode dizer sobre a noção de emancipação, posto que, além de os sistemas não apresentarem teleologia, emancipar-se na abordagem luhmanniana é quase uma impossibilidade, seja pelo fato da impossibilidade de alienação, seja pelo fato de que o pertencimento à dimensão sistema/entorno é inescapável.

\section{AS ESTRUTURAS AUSENTES DO ESTRUTURA- LISMO}

Claude Lévi-Strauss propôs transpor, da linguística moderna para as ciências sociais, os fundamentos epistemológicos que deram sustentação ao estruturalismo como movimento teórico. Tais fundamentos constituíam-se em estruturas inteligiveis subjacentes a diferentes objetos que, para além de sua aparente organização, os determinavam. Em "antropologia Estrutural”, Lévi-Strauss (2003, p. 48-49) afirma que: “'sistemas de parentesco', como os sistemas fonológicos, são elaborados pelo espírito no estágio do pensamento inconsciente (...) faz crer que em ambos os casos, os fenômenos observáveis resultam do jogo de leis gerais, mas ocultas".

A linguística moderna, proposta por Ferdinand de Saussure, apresentada na Universidade de Genebra, em seus cursos de linguística geral, entre 1906 e 1911, afirmava que a língua era um sistema, cujos elementos se comportavam de maneira relacional, formando diferentes níveis estruturais. Ao propor a distinção entre língua e 
fala, Saussure dizia que a língua poderia ser entendida como uma instituição social, ao passo que a fala como um ato de cada indivíduo. Assim, os diferentes arranjos dos atos de fala estariam subordinados às leis dessa estruturação social. Em outros termos, para Saussure, o sistema linguístico conservava-se independente dos atos de fala concretos dos indivíduos e possibilitava, como sistema ou estrutura não manifesta (ausente) no momento da fala, os atos de fala. A língua constituía-se, assim, em um sistema organizado por sinais, independente e atemporal (Rodrigues, 2011).

Essa lógica fundante da linguística moderna, que destaca a noção de ausência determinante (as estruturas), ficou conhecida na obra de Lévi-Strauss chamada de "Antropologia Estrutural". Ele estava convicto de que a mesma possibilidade de identificação de leis estruturais, nos diferentes níveis que estruturam o sistema linguístico, poderia ser encontrada nas diferentes sociedades. Sendo assim, as estruturas (não manifestas) constituíam-se em condições de possibilidades para a manifestação de diferenças culturais que estão sempre sobredeterminadas por uma mesma lógica estrutural. O estruturalismo, proposto por Lévi-Strauss, tinha como ponto de partida a necessidade de tornar inteligível, apreensível, pelo investigador, as diferentes relações que constituíam o(s) sistemas(s) subjacente(s) à vida social. Como ocorria com a fala na linguística, as práticas sociais também eram sobredeterminadas por uma lógica estrutural em nível subconsciente (Rodrigues, 2011).

Lévi-Strauss, nos anos próximos a II Grande Guerra, estava impregnado por uma visão "cientificista pura" da realidade. Nos Estados Unidos, quando esteve na década de 40, acompanhava os avanços, sem precedentes, das ciências bélicas. Isso fica claro quando, ao se referir à necessidade de uma maior cientificidade às ciências sociais argumenta, em "Antropologia Estrutural" (1970, p. 49), que "a fonologia não pode deixar de desempenhar, perante as ciências

[1] Em 1941 Lévi-Strauss viaja para Nova York para lecionar na "New School for Social Research", conhecendo e se tornando amigo do linguista Roman Jakobson, participando, inclusive, de seus cursos sobre linguística. É a partir de então que Lévi-Strauss percebe a potencialidade da linguística para se pensar os distintos fenômenos culturais. 
sociais, o mesmo papel renovador que a física nuclear, por exemplo, desempenhou, no conjunto das ciências exatas". Ao se referir aos sistemas de parentesco, afirma que ele desenvolve uma mesma lógica em que há dos sistemas linguísticos, e que, sendo assim, "formas de parentesco, regras de casamento, atitudes identicamente prescritas entre certos tipos de parentes, etc., faz crer que em ambos os casos, os fenômenos observáveis resultam do jogo de leis gerais, mas ocultas" (Lévi-Strauss, 49-50 [grifos nossos]). Assim, o estruturalismo prometia o tão desejado estatuto de cientificidade, perseguido pelas ciências sociais desde sua concepção, com Durkheim e outros, livrando-se, no entanto, das marcas biologistas que pautavam as analogias entre a sociedade e organismos vivos.

Dessa forma, a partir de uma perspectiva epistemológica, também podemos resumir o estruturalismo em alguns tópicos, quais sejam:

a) Em Durkheim, boa parte da sua teorização social está fundada no método observacional. Ao propor o fato social, promove uma ruptura entre o sujeito observador e o objeto observado, acreditando que o observador possa captar os elementos que o objeto revela. O estruturalismo, em termos de fundamentação epistemológica, faz algo muito semelhante, desta vez, porém, com a utilização dos fundamentos da linguística, para não buscá-lo nas ciências naturais.

b) O estruturalismo, portanto, nasce fundado numa epistemologia de caráter também positivista, uma vez que aquilo que se observa em uma determinada sociedade (sua cultura) é o resultado de leis estruturais (ocultas) que sobredeterminam completamente as manifestações culturais;

c) Quando Lévi-Strauss propõe a existência de leis gerais, denota o caráter de uma positividade pelo fato de que esses objetos determinantes - estruturas subjacentes à ordem social - apresentam regularidades para além do tempo e 
do espaço, e estas podem ser teorizadas como uma "lei natural", isto é, inerente ao fenômeno social.

d) O êxito do estruturalismo francês, mesmo que curto, devese, em parte, ao fato de que a sociologia, em particular a francesa, sempre aspirou a construir uma "verdadeira ciência" nos termo de uma epistemologia de orientação analítica e não histórica.

Para alguns setores do pensamento social, as teorias que emergiram com maior vigor a partir da crise do estruturalismo - algumas a partir da crítica do próprio movimento estruturalista ainda na década 60 -, isto é, a partir da década de 70, e seguiram em sua formulação e divulgação pelos anos 80, buscaram articular teorias da ação com teorias da estrutura e foram incluídas, por alguns autores, sob uma mesma etiqueta: pós-estruturalistas. Evidentemente que a noção de pós-estruturalismo, na teoria social, tem significado muito mais que a mera articulação dos aspectos subjetivos da ação e dos aspectos objetivos da estrutura.

Autores que têm produzido teorias sociais contemporâneas autodenominados pós-estruturalistas ou não-como Pierre Bourdieu, Ernesto Laclau, Anthony Giddens, têm buscado resgatar o sujeito (a ação) que ficou totalmente alijado na teorização estruturalista, e articular a sua ação com a noção de estrutura. Tais autores também têm procurado - uns mais outros menos -, dar maior movimento e interação às noções de subjetividade e objetividade, para explicação da realidade social contemporânea. Entretanto, boa parte das teorias, vistas como pós-estruturalistas, de um modo ou de outro, estão, quando comparadas à proposta Luhmanniana, vinculadas à tradição teórico-epistemológica das ciências sociais no que diz respeito aos seguintes pontos (ou pelo menos a alguns deles): 


\section{Tradição versus Luhmann}

\begin{tabular}{|c|c|}
\hline $\begin{array}{l}\text { Principais aspectos epistêmico- } \\
\text { metodológicos na tradição das } \\
\text { ciências sociais }\end{array}$ & $\begin{array}{l}\text { Principais aspectos epistêmico- } \\
\text { metodológicos na abordagem } \\
\text { luhmanniana }\end{array}$ \\
\hline $\begin{array}{l}\text { Existe sujeito observador e objeto ob- } \\
\text { servado numa realidade empiricamen- } \\
\text { te dada. }\end{array}$ & $\begin{array}{l}\text { Não existe nem sujeito nem objeto ob- } \\
\text { servado. O que existe são sistemas numa } \\
\text { realidade empiricamente dada. }\end{array}$ \\
\hline $\begin{array}{l}\text { Os métodos de conhecimento são } \\
\text { centralmente o observacional (empi- } \\
\text { rismo) ou intelectual (racionalismo); } \\
\text { compondo o que se chama de método } \\
\text { indutivo-dedutivo. }\end{array}$ & $\begin{array}{l}\text { Observações são vistas como operações } \\
\text { de distinção sistêmicas. Os sistemas po- } \\
\text { dem auto-observarem-se ou observam as } \\
\text { observações de múltiplas ordens (segun- } \\
\text { da, terceira...). }\end{array}$ \\
\hline $\begin{array}{l}\text { O sujeito apresenta um lugar privile- } \\
\text { giado na relação sujeito-objeto }\end{array}$ & $\begin{array}{l}\text { Não há sujeito ou objeto; existem siste- } \\
\text { mas. O que na tradição chama-se de in- } \\
\text { divíduo, sujeito ou ator, em Luhmann é } \\
\text { visto como sistema psíquico. }\end{array}$ \\
\hline $\begin{array}{l}\text { Modelos teóricos clássicos pendem para } \\
\text { a sociologia da ação, para a sociologia da } \\
\text { estrutura ou articulam ambos modelos. }\end{array}$ & $\begin{array}{l}\text { No modelo sistêmico não existem nem } \\
\text { ação nem estrutura, somente sistema e en- } \\
\text { torno que coexistem, coevoluem e se auto- } \\
\text { transformam a partir de irritações. }\end{array}$ \\
\hline $\begin{array}{l}\text { Modelos teóricos, em muitos casos, } \\
\text { fundamentam-se em dimensões onto- } \\
\text { lógicas. }\end{array}$ & $\begin{array}{l}\text { A teoria sistêmica de Luhmann funda- } \\
\text { menta-se no fato de que existem siste- } \\
\text { mas autopoiéticos, os quais reduzem a } \\
\text { complexidade mediante complexidade. }\end{array}$ \\
\hline $\begin{array}{l}\text { Modelos teóricos, em alguns casos, } \\
\text { trazem implícita ou explicitamente } \\
\text { uma dimensão normativa. }\end{array}$ & $\begin{array}{l}\text { Os sistemas constituem-se de códigos bi- } \\
\text { nários vinculados a sua qualidade auto- } \\
\text { poiética; portanto não podem normatizar } \\
\text { outras unidades ou totalidades. }\end{array}$ \\
\hline $\begin{array}{l}\text { Modelos teóricos, em alguns casos, são } \\
\text { ontologizados e/ou teleologizados. }\end{array}$ & $\begin{array}{l}\text { Não existe normatização ou prescrição; } \\
\text { não existe um dever ser; tampouco existe } \\
\text { um telos - toda teleologia está voltada para } \\
\text { a manutenção do sistema (autoteleologia). }\end{array}$ \\
\hline $\begin{array}{l}\text { A tradição está inserida em um para- } \\
\text { digma linear, em termos de conheci- } \\
\text { mento científico. }\end{array}$ & $\begin{array}{l}\text { A proposta luhmanniana está inserida em } \\
\text { um paradigma complexo, em termos de } \\
\text { conhecimento científico. }\end{array}$ \\
\hline
\end{tabular}




\section{A CRÍTICA LUHMANNIANA}

Para Luhmann, é necessária a construção de um modelo explicativo da sociedade moderna que dê conta de sua atual complexidade e que também abandone determinados pressupostos ontológicos - na visão luhmanniana, tornaram-se obstáculos epistemológicos ${ }^{1}$ - que têm pautado a maior parte dos esforços para o conhecimento da sociedade. Dentre esses pressupostos ontológicos e obstáculos epistemológicos, Luhmann (1998, pp. 52-53) tem apontado alguns, quais sejam:

A ideia de que a sociedade é formada por homens, por indivíduos humanos e pelas relações que esses indivíduos estabelecem entre si. Esse pressuposto tem gerado, desde os primórdios da sociologia como uma disciplina autônoma do conhecimento científico, um intenso debate - ação versus estrutura; subjetividade versus objetividade - que tem atravessados diferentes tradições, escolas, correntes e autores. Nesse sentido, temos tradições tais como a rousseauniana, em que interesses individuais podem ser articulados; também a perspectiva durkheimiana de solidariedade orgânica, que mantém junta toda e qualquer diferença que, num ato solidário e altruísta, como partes de um organismo, convive harmonicamente com toda e qualquer diferença; ou então, como em Marx, que, num dado momento, o proletariado como unidades individuais ou como massa se tornará "autoconsciente" e emergirá do processo de alienação ao qual fora submetido por muito tempo. O filme "Matrix" (2003) é uma excelente metáfora, na qual o protagonista Keanu Reeves desperta de sua alienação - no caso, através da tecnologia - e parte para a revolução armada.

Para Luhmann, pensar as sociedades como sendo pertencentes a regiões geográficas delimitadas, como, por exemplo: países, estados nacionais, culturas, etc., seria o mesmo que conceber um

[1] Luhmann (1998, p. 52) faz menção ao termo original: obstacles épistémologiques, utilizado por Gaston Bachelard. 
fenômeno social delimitando-o espacialmente, impondo-lhe uma dimensão de distinção totalmente arbitrária, em que estaria sendo levado em conta domínios ou valores, em detrimento da multiplicidade e da complexidade das comunicações. A concepção de que a sociedade pode ser observada a partir de fora, não apenas é equivocada, e se constituiu quando do surgimento da Ciência. Deve-se lembrar de que o nascimento da sociologia como ciência, dá-se em um momento em que a Ciência já existia e já havia formalizado seu método: o observado encontra-se fora do observador, estabelecendose a (suposta) objetividade do conhecimento.

A quase totalidade de abordagens teóricas clássicas, e mesmo as contemporâneas, partem do pressuposto epistemológico (profundo) de um modelo criacionista. Esse modelo, nas suas múltiplas versões clássicas, tem como elemento central a concepção de causação, isto é, algo ou um estado foi causado por algo ou um estado anterior. Moeller ilustra bem essa questão quando afirma que:

"Se o mundo é concebido sobre as bases da noção de causação, ou de um desígnio intencional, então a produção pode ser concebida como o resultado de um 'produtor' externo, sendo este produtor um demiurgo (como em Timeu de Platão), uma 'causa primeira' (como em Aristóteles), ou um Deus Criador (como no cristianismo)." (2006, p.13).

De fato, a ideia de "principialidade" tem sido cognitivamente confortável na perspectiva epistemológica ocidental de Ciência. A concepção de que existe um princípio, uma intenção, um projeto, uma consciência, que sabe de onde partir e para onde ir, como em Platão, cuja ordem e a beleza do cosmo provêm do resultado de uma intervenção intencional e racional de um artesão divino, o Demiurgo, que privilegia o bem e que impõem uma ordem (matemática) a um caos preexistente, produzindo, assim, a organização universal, tem-se constituído em uma das principais dimensões ontológicas da explicação científica. 
Luhmann propõem uma ruptura radical e definitiva com esta concepção criacionista ou causacional. Esse giro epistemológico desencadeará consequências importantes na forma de conceber o funcionamento do universo social. Uma série de conceitos até então derivados da própria ideia de principialidade e causação (sujeito, objeto, estrutura, função, comunicação etc.) apresentam-se (re) significados com relação à tradição. Se for tomada a relação entre sujeito e objeto, por exemplo, relação esta que tem sido discutida e problematizada em diferentes abordagens epistemológicas - positivista, estruturalista, materialista histórica, hermenêutica, fenomenológica etc. -, verificar-se-á que, na proposta luhmanniana, essa relação perde a sua centralidade, mais que isso, ela desaparece. Deixa de existir um sujeito conhecedor e um objeto a ser conhecido da forma como diversas correntes têm proposto até então.

Isso ocorre justamente porque Luhmann propõe que a sociedade seja vista como um sistema autopoiético. É importante que se lembre de que o autor da teoria sistêmica não está propondo que se introduza o conceito de autopoiésis, forjado na biologia para a compreensão dos sistemas vivos no interior da sociologia, como fora feito nos primórdios da disciplina, sob a égide do positivismo. Essa percepção é totalmente equivocada e infelizmente uma das principais críticas direcionadas a Luhmann. Uma leitura mais atenta desse autor irá demonstrar indubitavelmente que ele está propondo que as características identificadas em sistemas vivos, as quais foram tomadas para se pensar, para se construir um conceito teórico, a autopoiésis, podem ser - salienta-se: as mesmas características - encontradas em outros tipos de sistema, tais como o psíquico e o social. Para Luhmann, a realidade social pode ser mais competentemente apreendida, compreendida a partir da perspectiva sistêmica autopoiética, que se constitui num avanço teórico para o entendimento da realidade social (e não apenas social) e da sua complexidade. Conforme Luhmann: 
"A única coisa que exige o conceito de autopoiésis é que toda a explicação deve partir das operações especificas que reproduzem o sistema: tanto o explicado com quem o explica. Porém, este conceito não diz nada sobre que estruturas especificas têm se desenvolvido em tais sistemas e as causas dos acoplamentos estruturais entre sistema e entorno. Não explica os estados históricos do sistema (...) a autopoiésis é, então, sobretudo, a produção de indeterminação interna do sistema que só pode produzir-se através da construção de estruturas sistêmicas próprias." (2007 [grifos do autor])

\subsection{Nem sujeito, nem objeto}

Isso posto, uma das primeiras e mais evidentes implicações da noção de autopoiésis, no que diz respeito à relação sujeito-objeto, é a de que tanto o sujeito cognocente, que, para Luhmann, se constitui num sistema psíquico, como a sociedade, que se constitui num sistema social, não podem, conforme determina a noção de autopoiésis, comunicarem-se diretamente. O sistema psíquico (na tradição: o agir, o indivíduo, o sujeito) é entorno do sistema social e vice-versa, sendo assim, o conhecimento que o sistema psíquico consegue apreender acerca do sistema social sempre será um autoconhecimento, uma autodescrição. Isso se deve à improbabilidade da comunicação, inclusive entre sistemas psíquicos (pessoas), dado o fechamento operativo de cada sistema na construção - sempre a partir de seus próprios elementos- daquilo que conhecemos como conhecimento, entendimento ou nexo. O limite desse argumento proposto por Luhmann com relação à sociedade leva inexoravelmente a admitir que sociedade, como um sistema autopoiético formado por comunicações que se estabelecem recursivamente, é um sistema que se autodescreve. Luhmann $(1998 ; 2007)$ argumenta que se a sociedade é um sistema autopoiético de comunicações, e se as teorias sobre a sociedade constituem-se em comunicações científicas sobre o próprio objeto sociedade, então, essas comunicações são autológicas, 
isto é, a sociedade é descrita pela própria sociedade. ${ }^{1}$ Nas palavras do autor:

"Até início deste século [século XX] a teoria do conhecimento concebia sujeito e objeto como realidades separadas (...) as teorias da sociedade são teorias sobre a sociedade, feitas na sociedade (...) em outras palavras, o conceito de sociedade tem que ser construido autologicamente (...) fora da sociologia isto é um acontecimento muito comum. O conceito de autologia procede da linguística." (1998, p. 53).

Ao problematizar a relação sujeito e objeto a partir da autorreferência, iremos perceber que cessa uma relação assimétrica entre conhecedor e conhecido. Tratam-se, antes, de sistemas e entorno(s), pois tudo o que não for o sistema em questão, isto é, o sistema observado, será entorno, ambiente, mesmo os diferentes tipos de sistemas que coexistem na mesma dimensão espaço-temporal. Nesse sentido, não se trata mais de falar de um sujeito conhecedor, tomando-se o sistema psíquico como sujeito, ou de uma sociedade a ser conhecida, tomando-a como objeto. Para Luhmann, a existência do sujeito e do objeto, tão cara à tradição vétero-ocidental, como dimensão da sua ontologia simplesmente desaparece.

A autorreferência também permite que sejam superadas questões da tradição epistemológica, que privilegia a relação sujeito -objeto como dimensão fundamental do processo de conhecimento, cujas respostas são insatisfatórias, tais como: na relação sujeito e objeto, como se distingue um do outro? Do que é que o sujeito está se distinguindo? Do mundo? Dos objetos do mundo? De outros sujeitos ou de si próprio? Do não-eu? (Luhmann, 2007; Rodríguez; Torres, 2008). A autorreferência também busca responder a questões epistemológicas clássicas, que foram objetos de debates imemoráveis não apenas no século XIX, mas durante todo o século XX. Esses debates

[1] Não é sem razão que uma das últimas obras de Luhmann em que o autor busca sistematizar a sua teoria social desenvolvida ao longo de sua vida chama-se Die Gesellschaft der Gesellschaft, a "Sociedade da Sociedade". 
giravam em torno da relação sujeito-objeto e dos limites da indução. Neste caso, destacam-se três eixos principais:

a) Quanto à garantia lógica, fundante, de que observações de fatos particulares sempre garantem a sua generalização (o chamado indutivismo ingênuo).

b) A tese Duhem-Quine, também chamada de "princípio da subdeterminação", que argumenta que as teorias científicas são subdeterminadas pelos dados da observação. Posto que se é verdadeiro que as teorias partem de um número sempre finito de observações, é possível desenvolver um número infinito de teorias para aquele número finito de observações.

c) A tese da Carga Teórica, que se baseia no fato de que as observações estão sempre "carregadas", impregnadas de uma "teoria" a priori, significando que, na prática cotidiana da ciência, os cientistas não observam isentos de suas orientações teóricas, seus olhares dirigidos aos diferentes objetos estão "contaminados" por uma "carga" teórica que pode condicionar a própria observação. (Rodrigues, 2005, pp.114-115).

Ao se pensar em sistemas autorreferenciados e autopoiéticos e, considerando-se que indivíduos, na sua dimensão cognitiva, constituem-se de sistemas psíquicos e a sociedade de sistema social, mas que esses sistemas não podem se comunicar diretamente e se constituem um como entorno do outro, então, tanto o(s) sistema(s) psíquico(s) como o(s) sistemas(s) social(is) podem ser considerados - levando-se em conta a tradição epistemológica que os separa radicalmente - ou objeto ou sujeito. Se for considerado também que a observação sempre se constitui numa operação de distinção, e que todo sistema autopoiético - dado seu próprio acoplamento estrutural e sua diferenciação do entorno - observa/opera a partir de seus próprios elementos, com relação ao entorno, visando à manutenção da sua sistematicidade, desaparece o lugar privilegiado do sujeito como pessoas, indivíduos e dos objetos, como objetos no mundo, 
designados como tal, por um observador. O que temos são sistemas que se diferenciam por meio de operações/observações que se autorrealizam. Luhmann (1998, p. 59) é bastante claro com relação a isso ao se referir à sociedade e aos sistemas psíquicos. Diz o autor: " a sociedade é um sistema auto-observador e autodescritivo (...) não existe um observador externo possuidor de uma de competência [para observar] sequer parcial".

\subsection{Ser e não-ser: a ontologia do ser}

A autologia sistêmica proposta por Luhmann vai apresentar importantes implicações na tradição epistêmico-ontológica grecoromana-cristã. Ao discutir a dimensão ontológica do conhecimento ocidental, Luhmann vai argumentar que a raiz primeira de toda a ontologia está fincada na concepção do ser em contraposição ao nãoser; nas palavras do autor:

"Designamos como ontologia o resultado de uma forma de observar que parte da distinção ser/não-ser e que todas as demais distinções estão subordinadas a essa distinção. Esta distinção tira sua plausibilidade inconfundível do pressuposto de que unicamente o ser é e que o não-ser não é." (Luhmann, 2007, p. 710).

Para Luhmann, a metafísica ontológica que pautou o desenvolvimento do conhecimento e da ciência ocidentais, amparada pela lógica bivalente (a lógica clássica), isto é, aquela do terceiro excluído para o qual algo é ou não é, e não pode ser e não ser ao mesmo tempo, tem limitado o conceito de mundo, uma vez que o mundo não pode designar-se como indeterminação (nem ser, nem não ser).

É justamente essa dimensão ontológica, isto é, a existência necessária de um "ser privilegiado", o sujeito, com relação aos demais "seres" do mundo, aquilo que é designado como objetos, pelos sujeitos, que dificulta o entendimento de sistemas autopoiéticos. 
Uma vez que tais sistemas estabelecem uma dimensão autorreferenciada - designação de sua relação consigo mesmo - e, em decorrência disso, constituem-se em unidades que se autodiferenciam, não há lugar "privilegiado" (hierárquico) para nenhum tipo de sistema autopoiético, seja orgânico, psíquico ou social. É por esse motivo que Luhmann (2007, p. 20) afirmará que: "As investigações que este livro [La sociedad de la sociedad] apresenta buscam dar o passo em direção a um conceito de sociedade radicalmente antihumanista, radicalmente antirregionalista e radicalmente construtivista".

As implicações do radicalismo anti-humanista vão se estender à noção de teleologia. Um telos, uma finalidade, sempre esteve presente de modo explicito ou implícito, na tradição teórica sociológica. Em Marx, por exemplo, a mais-valia, se constitui na finalidade clara do entesouramento do capitalista e da alienação do proletariado; já em Durkheim, a divisão social do trabalho tinha a função de manter as sociedades orgânicas coesas. Aliás, um dos traços da escola funcionalista, fundamento de muitas abordagens sociológicas, traz sempre a noção de finalidade: a função se constitui num objetivo (último) que deve ser alcançado. Entretanto, para Luhmann (2007, p. 589) os sistemas, ao se diferenciarem, diferenciam-se internamente de modo funcional. Isso significa que o sistema social se diferencia em sistemas funcionais. Nos termos de Luhmann (p. 591 [grifos do autor]), "diferenciação funcional significa que o ponto de vista da unidade sob o qual tem se diferenciado uma diferença de sistemal entorno é a função que o sistema diferenciado (e não o seu entorno) desempenha para o sistema total". Em outros termos, cada sistema funcional relaciona-se com um entorno "interno" ao sistema total como se fosse um subsistema do sistema social, e tal diferenciação cumpre uma função específica. Pois bem, retornando à questão da teleologia, mesmo Luhmann, admitindo a diferenciação funcional do sistema, argumentará que:

“Os sistemas de função não são teleológicos. Referem todas as suas operações a uma distinção entre dois valores - 
precisamente os do código binário. (...) Em um sentido estrito os códigos binários são formas, isto é, formas de dois lados, que facilitam a passagem de uma parte a outra, o transito de ida e volta entre o valor e o valor oposto..." (Luhmann, 2007, pp. 593-94).

Conforme os termos propostos por Luhmann na citação anterior, os meios simbolicamente generalizados tornam-se binários no sentido de aceitação/negação, ocorrendo necessariamente e exclusivamente a distinção entre dois valores: na diferenciação sistema-político, entre poder/não poder; na diferenciação sistema-ciência, entre verdade/não verdade; na diferenciação sistema-religião, entre fé/não fé. Essa binarização suprime toda e qualquer teleologia do sistema que, de fato, é incompatível com a autopoiésis. Luhmann (2007, p. 593[grifos do autor]) acrescenta que: "para especificar a função [do sistema] deve-se dar, pois, um código cuja função consiste em assegurar que a autopoiésis continue a impedir que o sistema se imobilize ao atingir um fim (fine, telos) e, assim, deixe de operar".

Estes são apenas alguns aspectos de caráter epistemológico, teórico e metodológico da rica obra de Niklas Luhmann, que, durante quase toda a sua vida intelectual, dedicou-se à construção de uma nova teoria para a sociedade. O referido autor deixou uma produção de milhares de páginas, que certamente será objeto de muita investigação neste século que recém se inicia. Sua obra, sem dúvida, levará muitos anos para ser conhecida em toda a sua potencialidade e certamente envolverá, como já tem envolvido, pesquisadores do mundo inteiro.

\section{REFERÊNCIAS}

ANDRADE Mariano; PIVE, Adrián; PIZZI, Alejandro. O individualismo metodológico de Max Weber. In: Epistemolgía de las ciências sociales. Buenos Aires: Jorge Baudino Edicines, 2007. (p. 57-78). 
COMTE, Auguste. Curso de filosofia positiva. In: Os Pensadores. São Paulo: Abril Cultural, 1983.

DURKHEIM, Emile. As Regras do Método Sociológico. São Paulo: Nacional, 1982.

FLICKINGER, Hans-Georg. O lugar do novo paradigma no contexto da teoria moderna do conhecimento. In: FLICKINGER, Hans-Georg e NEUSER, Wolfgang. Teoria de Auto-organização: As Raízes da Interpretação Construtivista do Conhecimento. Porto Alegre: EDIPUCRS, 1994, pp.23-45.

LEVINE, Donald N. Visões da tradição sociológica. Rio de Janeiro: Zahar, 1997.

LÉVI-STRAUSS, Claude. Antropologia Estrutural. Rio de Janeiro: Tempo Brasileiro, 2003.

. Antropologia Estrutural. Rio de Janeiro: Tempo Brasileiro, 1970.

LUHMANN, Niklas. Sociedad y Sistema la Ambición de la Teoria. Barcelona, Buenos Aires, México: Ediciones Paidós; I.C.E la Universidad Autónoma de Barcelona, 1990.

Sistemas Sociales: Lineamentos para una Teoría General. Rudí (Barcelona): Anthropos; México Universidad Iberoamericana: Santa Fé de Bogotá: CEJA, Pontifícia Universitdad Javeriana, 1998.

La sociedad de la sociedad. México: Iberoamericana/Herder, 2007.

MARX, Karl. Manuscritos econômico-filosóficos. Disponível em: http:// www.marxists.org/portugues/marx/1844/manuscritos/index. htm\#topp 
O método da economia política. In: Os Pensadores. São Paulo: Abril Cultural, 1978.

MOELLER, Hans-Georg. Luhmann Explained: from souls to systems. Illinois: Open Court, 2006.

RITZER, George. Teoria Sociológica Clássica. Madrid: McGraw, 1993.

RODRIGUES, Léo Peixoto. O Estruturalismo Francês: aspectos históricos e epistemológicos. In: SCHULZ, Rosângela (Org.). Ensaios de Sociologia e Política. Pelotas: UFPel, 2010. (p. 133-175).

- Introdução à Sociologia do Conhecimento, da Ciência e do Conhecimento científico. Passo Fundo - RS: UPF, 2005.

RODRÍGUEZ, Dario R.; TORRES, Javier N. Introducción a la teoría de la sociedad de Niklas Luhmann. México: Iberoamericana/Herder, 2008.

WEBER, Max. Economia e Sociedade. Brasília, UnB; São Paulo, Imprensa Oficial, 2004.

Recebido em: 20/04/2012

Aprovado em: 22/05/2012 